Geopolítica(s) Revista de estudios sobre espacio y poder ISSN: 2172-3958

\title{
La Alianza del Pacífico: una integración post-neoliberal
}

Isabel Rodríguez Aranda y Edgar Vieira Posada (eds.) (2015) Perspectivas y oportunidades de la Alianza del Pacífico. Bogotá: Colegio de Estudios Superiores de Administración (CESA) / Centro de Estudios sobre Globalización e Integración (CEGLI), Tomo V. 391 pp. ISBN 978-958-8722-78-8.

Las nuevas configuraciones de poder en la América Latina de hoy exigen un análisis cauteloso y riguroso sobre las proyecciones y prospectivas a realizarse. Las piezas a mover en el tablero geopolítico regional dependen en gran medida de los proyectos nacionales de los gobiernos de turno, de su corte ideológico, y en su caso, del impulso, que puedan o no, recibir de otras potencias a nivel subregional y a nivel global. En este contexto, la Alianza del Pacífico (AP) se planta como alternativa o contrapropuesta a proyectos latinoamericanos $-\mathrm{y}$ en particular sudamericanos - previos como la Unión de Naciones Sudamericanas (UNASUR), el Mercado Común del Sur (MERCOSUR), y la Alianza Bolivariana para los Pueblos de nuestra América (ALBA). La AP, en medio de la disputa por el liderazgo político y económico regional, se muestra como un nuevo ejercicio de integración, el más reciente, que presume una nueva dinámica de poder y discurso. Un modelo que no puede dejar de analizarse sin entenderse dentro del marco de la rivalidad de las dos potencias latinoamericanas: México y Brasil. Por un lado, el principal impulsor de la AP, México, con su influencia en Centroamérica y el Caribe, su liderazgo demostrado en la también reciente Comunidad de Estados Latinoamericanos y del Caribe (CELAC), y bajo la línea del mandato neoliberal de Washington; por otro lado, Brasil, con su influencia y liderazgo en Sudamérica y MERCOSUR, y su propuesta de desarrollo social dentro del espectro de la izquierda latinoamericana.

Desde la perspectiva de los autores de esta obra, la AP, enmarca una oportunidad de integración regional que se diferencia sustancialmente a otros procesos latinoamericanos anteriores por su pragmatismo y dinamismo, sin aislacionismos ni cerrazones. La AP es una propuesta nacida en 2011, con la inclusión de los países de la costa del Pacífico latinoamericano (Chile, Colombia, México y Perú); cuya población asciende en su conjunto a más de 210 millones de personas. El objetivo de ésta, radica, fundamentalmente, en la apertura comercial y económica, de libre circulación de bienes y capitales; así también, como de su interacción con miras a un intercambio comercial ampliamente dirigido hacia la región Asia-Pacífico.

Con el objetivo de analizar y explicar las repercusiones que la AP trae consigo, el Centro de Estudios sobre Globalización e Integración (CEGLI) del Colegio de Estudios Superiores de Administración de Colombia, y el Centro de Estudios de Relaciones internacionales (CERI) de la Universidad del Desarrollo de Chile pre- 
sentan Perspectivas y Oportunidades de la Alianza del Pacífico. Entrega, de tipo colaborativa, que cuenta con la participación de académicas y académicos de universidades de los cuatro países signatarios, cuya intención es la de atender a las diferentes perspectivas y resultados presupuestados que se tienen desde sus países de origen para la AP, y de la AP hacia el exterior, así, como la de prever y analizar las consecuencias geopolíticas, pero sobretodo, económicas que puedan resultar de este nuevo experimento de proceso de integración en América Latina. A lo largo de los diez capítulos que integran esta obra, se abordan diversas temáticas como las relaciones económicas y comerciales de los cuatro países signatarios, los procesos internos para su integración a la nueva alianza, las repercusiones de la AP con los países del Atlántico latinoamericano, el nuevo balance de poder con respecto a otras potencias en la región (Brasil y Venezuela, particularmente), los tratados comerciales con la región Asia-Pacífico, las Cadenas Globales de Valor (CGV), la integración financiera de la AP, y el rol de China y los Estados Unidos ante esta nueva dinámica; entre otros temas.

Isabel Rodríguez y Edgar Vieira resaltan, a manera introductoria de la entrega, la importancia de un análisis profundo de una integración todavía en construcción. Un proceso basado en un proyecto que presenta características antes vistas en procesos de integración (sub)regionales previos (cerrados o abiertos), con fines políticos de diversa índole, y cuyo objetivo sea una integración de mercado común; pero que a su vez, se diferencia de otros proyectos al enfocarse, los miembros, conjuntamente a otra región en particular como lo es, Asia-Pacífico, y con la posibilidad de unirse a la ola de formación de Cadenas Globales de Valor (CGV), que en su opinión, resultan como el rediseño de las nuevas tendencias del comercio a nivel mundial. Rodríguez y Vieira, en su papel de coordinadores, manifiestan la oportunidad de reflexionar sobre la integración en América Latina que genera la AP, vista desde "su pasado, su presente y su futuro" (p. 25), y como una nueva alternativa de herramienta de desarrollo.

En el capítulo tercero, "Geopolítica de la Alianza del Pacífico en América Latina”, Alberto Rocha y Daniel Morales Ruvalcaba realizan un análisis geopolítico y geoeconómico entre los Estados miembros de la AP, entre éstos a nivel regional, entre México y Brasil como potencias rivales, entre la AP con los Estados Unidos y con la región Asia-Pacífico. Introducen en su análisis, la etapa que impera en la región latinoamericana, aquella que cuenta, en su opinión, con dos dinámicas geopolíticas marcadas: por un lado, la del "regionalismo semicerrado" regulado por el Estado y por otro, la del "regionalismo abierto" regulado por el mercado, que competen a la dicotomía entre Capitalismo de Estado y Capitalismo de Mercado. En este capítulo se proponen como herramientas de análisis la observación y ponderación de las capacidades nacionales para la comprensión "no solo del poder nacional/internacional, sino también el posicionamiento estructural en el sistema interestatal-internacional" (p. 108), al cual le atribuyen como un factor condicionante en la política exterior, en la geopolítica y en la geoeconomía de los Estados nacionales en cuestión. Es a través de estas herramientas de observación y ponderación, que los autores presentan un Índice de Poder Mundial, resultado de su propia categorización de lo que denominan Capacidades materiales, Capacidades semi-materiales y Capacidades inmateriales. 
Esta obra conjunta de autores de los cuatro países que actualmente la componen, y con posibles adiciones como Costa Rica y Panamá, demuestra el interés por descifrar, aún a los pocos años de su conformación, los alcances y oportunidades que representa la Alianza del Pacífico para los países que la componen, y para la región latinoamericana en su conjunto. Perspectivas y oportunidades de la Alianza del Pacífico, prima el carácter económico que se la da a la AP de acuerdo al potencial que un proceso (sub)regional, aún en desarrollo y expansión, puede significar para las arcas de los países miembros. Se echa de menos un análisis menos clásico sobre las nuevas configuraciones y relaciones de poder, por ejemplo, desde la perspectiva de la geopolítica crítica. Sin duda la falta de mapas, y las abundantes tablas e información con respecto al intercambio comercial y económico que atañen a los países en cuestión, y las de éstos hacia el exterior, desnudan la primacía y el objetivo de la obra.

La AP puede adquirir, en los años venideros, una relevancia mayor en la medida en que las configuraciones políticas e ideológicas giren o no hacia ella. La intención declarada de formar parte de este modelo de integración (sub)regional de corte postneoliberal, del recién electo presidente argentino es tan solo una muestra actual de ello. La velocidad con la que se ha echado a andar la AP, reflejada en sus diez cumbres llevadas a cabo desde 2011 a la fecha, y los nuevos objetivos que se han incluido (turismo, investigación, movilidad académica, oficinas compartidas de representación comercial —Estambul (Turquía) - y diplomática - Accra (Ghana) - , etc.), demuestran el interés nacional que se le ha impreso, así como las nuevas relaciones de poder a observarse en el futuro en la región.

Marco A. Trejo Picazo Universidad Complutense de Madrid Email: marcotpicazo@gmail.com 